\title{
Geleneksel Kahvaltılık Zahterin Antimikrobiyal Etkisi
}

\author{
Antimicrobial Effect of Traditional Breakfast Zahter
}

\section{Lütfiye KADIOĞLU DALKILIÇ*a , Semih DALKILIÇ ${ }^{\text {b İsmail KORKMAZ }}$}

Firat Üniversitesi, Fen Fakültesi, 23200, Elazı ̆̆

\author{
• Geliş tarihi / Received: 18.06.2019 • Düzeltilerek geliş tarihi / Received in revised form: 01.10.2019 • Kabul tarihi / Accepted: 23.10 .2019
}

\begin{abstract}
$\ddot{O} z$
Günümüzde bazı hastalıkların tedavisinde kullanılan preparatların etken maddeleri tamamen bitkisel kaynaklı olabilmektedir. Bazı bitkilerin veya baharat karışımlarının antiviral, antibakteriyel ve antifungal etkilerinin olduğu bilinmekte olup basit enfeksiyonların tedavi edilmesinde veya koruyucu olarak bağışıklık sisteminin güçlendirilmesinde takviye edici olarak kullanıldığı bilinmektedir. Çalışmada kullanılan zahter de özellikle Güneydoğu Anadolu Bölgesi'nde kahvaltılık olarak tüketilen bir baharat karışımıdır. Bu çalışmada; zahterin Escherichia coli ATCC 25322, Pseudomonas aeruginosa DMS50071 SCOTTA, Klebsiella pneumoniae ATCC 700603'ya karş1 oyuk agar yöntemi kullanılarak antimikrobiyal etkileri incelendi. Zahterin etanol ve kloroform ekstreleri 25mg/ml - 50mg/ml - 75mg/ml $100 \mathrm{mg} / \mathrm{ml}$ olarak uygulandı. Negatif kontrol için \%100 DMSO, pozitif kontrol için de amoksisilin, klindamisin ve penisilin kullanıldı. Sonuçlara göre; Zahter ekstraktının 25mg/ml-50mg/ml-75mg/ml ve $100 \mathrm{mg} / \mathrm{ml}$ konsantrasyonlarında (zon görülmedi, $18 \mathrm{~mm}, 24 \mathrm{~mm}, 27 \mathrm{~mm}$ ) kloroform ile hazırlanan ekstresinde $E$. coli 'ye karşı etki ettiği belirlendi. Zahter ekstraktının $25 \mathrm{mg} / \mathrm{ml}-50 \mathrm{mg} / \mathrm{ml}-75 \mathrm{mg} / \mathrm{ml}$ ve $100 \mathrm{mg} / \mathrm{ml}$ konsantrasyonlarında $(9 \mathrm{~mm}, 11 \mathrm{~mm}$, $14 \mathrm{~mm}, 27 \mathrm{~mm}$ ) kloroform ile hazırlanan ekstresinde $P$. aeruginosa ye gelişimini engellediği tespit edildi. Zahter ekstraktının $25 \mathrm{mg} / \mathrm{ml}-50 \mathrm{mg} / \mathrm{ml}-75 \mathrm{mg} / \mathrm{ml}$ ve $100 \mathrm{mg} / \mathrm{ml}$ konsantrasyonlarında $(13 \mathrm{~mm}, 17 \mathrm{~mm}$, zon yok, zon yok) kloroform ile hazırlanan ekstresinde $K$. pneumoniae karşı etki ettiği gözlendi. Zahter ekstraktının 25mg/ml- 50mg/ml$75 \mathrm{mg} / \mathrm{ml}$ ve $100 \mathrm{mg} / \mathrm{ml}$ konsantrasyonlarında $(13 \mathrm{~mm}, 17 \mathrm{~mm}$, zon görülmedi, zon görülmedi) etanol ile hazırlanan ekstresinde $K$. pneumoniae 'ye karşı etkili olduğu tespit edildi. Fakat $E$. coli'ye ve $P$. aeruginosa 'ya karşı etki etmedi. Ayrıca kloroform ile yapılan zahter ekstresinin, etanol ile yapılan zahter ekstresine göre daha güçlü bir antimikrobiyal etkiye sahip olduğu tespit edildi.
\end{abstract}

Anahtar kelimeler: Antimikrobiyal Aktivite, Aromatik Bitkiler, Baharat, Ekstrakt

\begin{abstract}
Today, the active ingredients of the preparations used in the treatment of some diseases can be completely herbal source. Some plants or spice mixtures are known to have antiviral, antibacterial and antifungal effects, and are known to be used as supplements to treat simple infections or to strengthen the immune system as a preservative. The zahter used in the study is a spice mixture that is consumed as breakfast in Southeastern Anatolia. In this study; The antimicrobial effects of zahterin Escherichia coli ATCC 25322, Pseudomonas aeruginosa DMS50071 SCOTTA, Klebsiella pneumoniae ATCC 700603 were investigated by using the hollow agar method. Zahterin ethanol and chloroform extracts were applied at $25 \mathrm{mg} / \mathrm{ml}-50 \mathrm{mg} / \mathrm{ml}-75 \mathrm{mg} / \mathrm{ml}-100 \mathrm{mg} / \mathrm{ml}$. 100\% DMSO for negative control and amoxicillin, clindamycin and penicillin for positive control were used. According to the results; Zahter extract was found to be effective against E. coli in its extract prepared with chloroform at concentrations of $25 \mathrm{mg} / \mathrm{ml}-50 \mathrm{mg} / \mathrm{ml}$ $75 \mathrm{mg} / \mathrm{ml}$ and $100 \mathrm{mg} / \mathrm{ml}$ (zone not seen, $18 \mathrm{~mm}, 24 \mathrm{~mm}, 27 \mathrm{~mm}$ ). It was determined that Zahter extract inhibited the development of $P$. aeruginosa in its extract prepared with chloroform at concentrations of $25 \mathrm{mg} / \mathrm{ml}-50 \mathrm{mg} / \mathrm{ml}-75 \mathrm{mg} /$ $\mathrm{ml}$ and 100mg $/ \mathrm{ml}(9 \mathrm{~mm}, 11 \mathrm{~mm}, 14 \mathrm{~mm}, 27 \mathrm{~mm})$. Zahter extract was observed to be effective against K. pneumoniae in its extract with chloroform at concentrations of $25 \mathrm{mg} / \mathrm{ml}-50 \mathrm{mg} / \mathrm{ml}-75 \mathrm{mg} / \mathrm{ml}$ and $100 \mathrm{mg} / \mathrm{ml}(13 \mathrm{~mm}$, $17 \mathrm{~mm}$, no zone, no zone). Zahter extract was found to be effective against $K$. pneumoniae in its extract with ethanol at concentrations of $25 \mathrm{mg} / \mathrm{ml}-50 \mathrm{mg} / \mathrm{ml}-75 \mathrm{mg} / \mathrm{ml}$ and $100 \mathrm{mg} / \mathrm{ml}$ (13mm, $17 \mathrm{~mm}$, no zone, no zone seen). But it did not affect E. coli and $P$. aeruginosa. In addition, zahter extract with chloroform was found to have a stronger antimicrobial effect than zahter extract made with ethanol.
\end{abstract}

Keywords: Antimicrobial Activity, Medical Plants, Spice, Extract

\footnotetext{
*Lütfiye KADIOĞLU DALKILIÇ; tkadioglu85@gmail.com, Tel: (544) 63786 60, orcid.org/0000-0002-6791-3811

${ }^{\mathrm{b}}$ orcid.org/0000-0002-6892-247X $\quad{ }^{\mathrm{c}}$ orcid.org/0000-0003-4631-7786
} 


\section{Giriş}

Bitkiler antik çağlardan beri gıdalara tat, koku ve renk vermek amaciyla kullanılmaktadır. Bitkiler ve uçucu yağları ilaç, gıda ve kozmetik gibi birçok sanayi alanında hammadde olarak kullanıldıklarından aynı zamanda da antimikrobiyal etkilere sahip olmalarından dolayı dikkatle incelenmiş ve önemli sonuçlara ulaşılmıştır. Antimikrobiyal aktivite gösteren bitkiler gıdalarda koruyucu madde, tıbbi amaçlı, antihelmintik, antimikrobiyal olarak ve bitki zararlılarına, yabancı otlara karşı mücadelede kullanılmaktadır (Faydaoğlu ve Sürücüoğlu, 2013). Günümüzde mikroorganizmaların hali hazırda kullanılan bazı antibiyotiklere karşı direnç geliştirmelerinden dolayı doğal bitkisel kaynakların önemi daha çok artmıştır. Dünyada bitkisel ilaç kullanımı her yıl \%10 ile \%20 oranında artış gösterdiği düşünülmektedir (Von Reis Altschul, 1997). Amerikan halkının üçte birinin bitkisel kaynaklı ilaç kullandığ 1 bilinmektedir (Husin, 2001 ve Azriani ve vd., 2008). İnsanları bitkisel ilaç kullanmaya yönlendiren farklı nedenler olabilir. Bunların başında o bölgenin gelenek ve görenekleri halkın inançları baskın olmakla birlikte alınan bitkilerin erişilebilirliğinin kolay olmasına ilaveten maliyetinin de ucuz olması tercih edilir olmasin1 sağlamıştır (Von Reis Altschul, 1997). Bazı bitkiler yiyeceklere aroma vermesinden dolay1 baharat olarak veya direk olarak kullanılmaktadır.

Bitki karışımlarından oluşan Zahterin kahvaltılık olarak kullanılması eski tarihlere dayanmaktadır. Zahterin İçeriği; menengiç (500gr), susam $(1 \mathrm{~kg})$, leblebi tozu $(1 \mathrm{~kg})$, karpuz çekirdeği $(500 \mathrm{gr})$, kavun çekirdeği (500gr), sumak (500gr), tuz (isteğe bağlı), kimyon (2 tatlı kaşı biber (isteğe bağl1), çörek otu (500gr), limon tuzu ( 1 çay kaşığ 1 ), kişniş (200gr), rezene (200gr) ve kekik (200gr) dahil birçok farklı baharatlardan oluşmaktadır.

Kahvaltı için bir kâseye zeytinyağı, bir kaseye zahter konulup ekmek ilk olarak zeytinyağına batırılarak daha sonra zahtere bandırılarak tüketilmektedir. Calıșmada; Zahter'in kloroform ve etanol gibi çözücüler kullanılarak antimikrobiyal aktivitesi oyuk agar ve minumum inhibisyon konsantrasyon metodları kullanılarak belirlenmesi amaçlandi.

\section{Materyal ve Yöntem}

Bu çalışmada kullanılan zahter ev yapımı olarak hazırlanmış olup, test edilen mikroorganizmalar,
Firat Üniversitesi Biyoloji bölümünden temin edilen Escherichia coli ATCC 25322, Pseudomonas aeruginosa DMS50071 SCOTTA, Klebsiella pneumoniae ATCC 700603'tür. Deneysel çalışma öncesinde bakteriler Nutrient Broth ve Mueller-Hinton Agar'da üretildi.

\subsection{Ekstrelerin Hazırlanışı}

50 gr Zahter, 7 gün boyunca $500 \mathrm{ml}$ etanol ve kloroform (Merck, Darmstadt) ile özütlendi. Süspansiyon oda sicaklığında 130 rpm'de 72 saat karıştırıp, sonra Whatman No 1 filtre kağıdıyla süzüldü. Birleştirilen öz, $40^{\circ} \mathrm{C}$ rotary evaporatörde buharlaştırıldı, özütleri elde etmek için karşıllık gelen çözücü içinde yeniden çözdürülüdü ve kullanımdan önce $4^{\circ} \mathrm{C}^{\prime}$ de saklandı (Güzeldağ ve vd., 2013).

Zahterin E. coli, P. aeruginosa, K. pneumoniae'ya karşı oyuk agar yöntemi kullanılarak antimikrobiyal etkileri incelendi. Zahterin etanol ve kloroform ekstreleri $\% 25 \mathrm{mg} / \mathrm{ml}-50 \mathrm{mg} / \mathrm{ml}$ $75 \mathrm{mg} / \mathrm{ml}-100 \mathrm{mg} / \mathrm{ml}$ olarak uyguland. Negatif kontrol için kuyucuklara \%100 dimetil sülfoksit (DMSO), pozitif kontrol için de amoksisilin $30 \mu \mathrm{g}$, klindamisin $2 \mu \mathrm{g}$ ve penisilin G $10 \mathrm{U}$ eklendi.

\subsection{Minimal İnhibisyon Konsantrasyon}

Oyuk agar difüzyon analizinde zahter aktivitesini gösteren minimum inhibitör konsantrasyon mikro seyreltme yöntemiyle belirlendi. 96 yuvalı mikro titrasyon plakasının tüm haznelerine nutrient broth $(100 \mu \mathrm{l})$ ilave edildi. $40 \mu \mathrm{l}$ zahterden A1-H1 kuyulara eklendi. Ve $100 \mu 1$ alınarak seri dilüsyon yapıldı. Her bir oyuğa test edilen bakterilerden inoküle $(4 \mu 1)$ edildi ve 24 saat $37^{\circ} \mathrm{C}^{\prime}$ de inkübe edildi (Buwa ve Van Staden, 2006).

\subsection{Minimal Bakterisidal Konsantrasyon}

$37^{\circ} \mathrm{C}$ 'de 24 saatlik inkübasyonun ardından, her dilüsyonun $3 \mu \mathrm{L}$ 'si, aynı koșullarda inkübe edilen Mueller Hington agar plakalarına birakıldı (3). Hücrenin biyositlere maruz kalması bir gün daha sürdürüldü. $\mathrm{Bu} 24$ saatlik numuneler $(3 \mu 1), 1-3$ gün inkübe edilen plaklara bırakıldı. Agardaki alt kültüründe üremenin olmadığ 1 en düşük broth konsantrasyonu minimum bakterisidal konsantrasyon (MBC) olarak kabul edildi (Martini vd., 2009 ve Gatta ve vd., 2003).

\section{Bulgular ve Tartışma}

Zahter'in Kloroform ile hazırlanan \%25'lik konsantrasyonu sirasiyla $K$. pneumoniae $(13 \mathrm{~mm}$ 
inhibisyon) ve $P$. aeroginosa (9mm inhibisyon zonu) nın gelişimini engellerken $E$. coli'ye karşı aktivite göstermediği belirlendi (Tablo 1). Hazırlanan \%100'lük konsantrasyonunda en yüksek zon çapını $E$. coli ve $P$. aeroginosa $27 \mathrm{~mm}$ belirlenirken $K$. pneumoniae'ye karş1 antimikrobiyal aktivite göstermediği tespit edildi (Tablo 1).

Tablo 1. Zahter/kloroform ekstresininin antibakteriyel etkisi (zon çapları mm)

\begin{tabular}{|c|c|c|c|c|c|c|c|c|}
\hline Bakteriler & Konsantra & Ionlar $(\mathrm{mg} / \mathrm{r}$ & Zon Çapları ( & & Zahter/ Kloroform & Klindamisin & Amoksisilin & Penisilin G \\
\hline & $25 \mathrm{mg} / \mathrm{ml}$ & $50 \mathrm{mg} / \mathrm{ml}$ & $75 \mathrm{mg} / \mathrm{ml}$ & $100 \mathrm{mg} / \mathrm{ml}$ & & & & \\
\hline E. coli & * & $18 \mathrm{~mm}$ & $24 \mathrm{~mm}$ & $27 \mathrm{~mm}$ & & $25 \mathrm{~mm}$ & $14 \mathrm{~mm}$ & * \\
\hline P. aeroginosa & $9 \mathrm{~mm}$ & $11 \mathrm{~mm}$ & $14 \mathrm{~mm}$ & $27 \mathrm{~mm}$ & & $25 \mathrm{~mm}$ & $*$ & * \\
\hline K. pneumonia & $13 \mathrm{~mm}$ & $17 \mathrm{~mm}$ & $*$ & $*$ & & $22 \mathrm{~mm}$ & $11 \mathrm{~mm}$ & * \\
\hline
\end{tabular}

\%25'lik Zahter ekstresinin kloroform çözeltisi $K$. pneumoniae'ya karş1 $13 \mathrm{~mm}, \quad \% 50$ ‘lik çözeltisindeki inhibisyon zonu $17 \mathrm{~mm}$ olarak belirlendi (Tablo 1). \%75'lik ve \%100'lük konsantrasyonlarda herhangi bir etki gözlenmedi (Tablo 1). Zahter in kloroform çözeltisindeki $\% 25, \% 50, \% 75, \% 100$ 'lük konsantrasyonları $P$. aeruginosa' nın gelişimini linear olarak engellediği gözlendi $(9,11,14,27 \mathrm{~mm}$ inhibisyon zonu) (Tablo 1). \%25'lik Zahter ekstresinin kloroform çözeltisi E. coli'ye karş1 etki göstermezken, \%50'lik konsantrasyonda $18 \mathrm{~mm}$ ile $\% 75^{\prime}$ lik konsantrasyonda $24 \mathrm{~mm}$ ile ve \%100'lük konsantrasyonda $27 \mathrm{~mm}$ zon çap1 olarak belirlendi (Tablo 1).

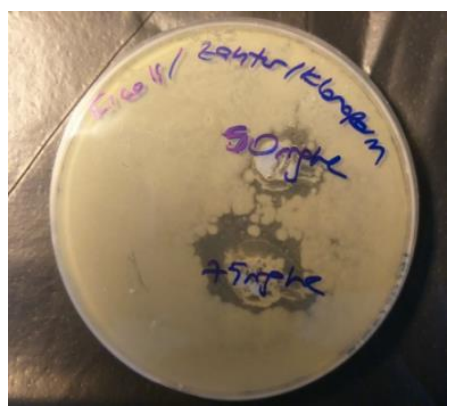

A

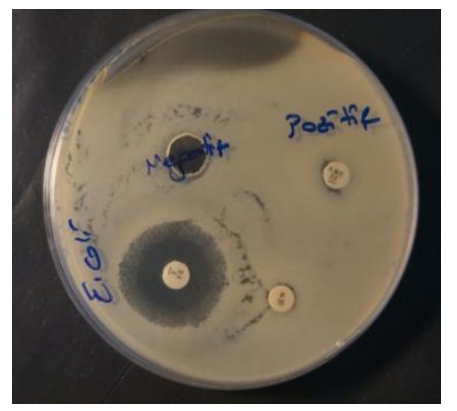

B

Şekil 1. A. E. coli'nin zahter ektresini kloroform çözeltisindeki inhibisyon zonları B. E. coli'nin negatif ve pozitifler kontrollere karşı oluşan zon çapları

\%25'lik Zahter ektresinin etanol çözeltisindeki inhibisyon zonu $K$. pneumoniae'ya karş1 $15 \mathrm{~mm}$ iken, \%50'lik çözeltisindeki inhibisyon zonu $26 \mathrm{~mm} \quad$ iken, $\% 75^{\prime}$ lik ve \%100'lük konsantrasyonda herhangi bir zon oluşturmadığ1 gözlendi (Tablo 2). Zahter ektresinin etanol çözeltisi $E$. coli ve $P$. aeruginosa' ya karş1 antimikrobiyal aktivite gösterdi (Tablo 2).

Tablo 2. Zahter/etanol ekstresinin antibakteriyel etkisi (zon çapları mm)

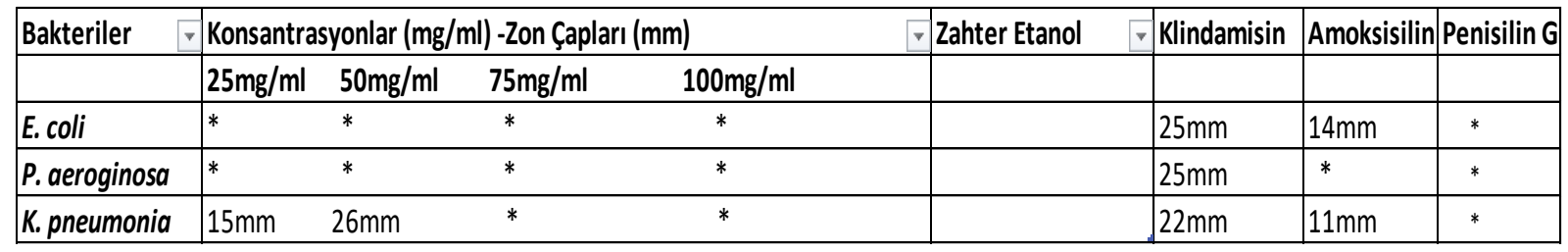

E. coli, Klindamisine karşı $25 \mathrm{~mm}$ çapında, amoksisiline karşı $14 \mathrm{~mm}$ çapında zon vermiş olup, penisiline karşı bir etkisi olmadığı belirlendi. Klindamisin $P$. aeruginosa'nın gelişimi engellerken $(25 \mathrm{~mm})$, penisilin ve amoksisilin gelişimini engellemediği tespit edildi. $K$. pneumoniae klindamisine karşı $22 \mathrm{~mm}$ çapında, amoksisiline karşı $11 \mathrm{~mm}$ çapında zon vermiş olup, penisiline karşı bir aktivite göstermedi (Tablo 2). 


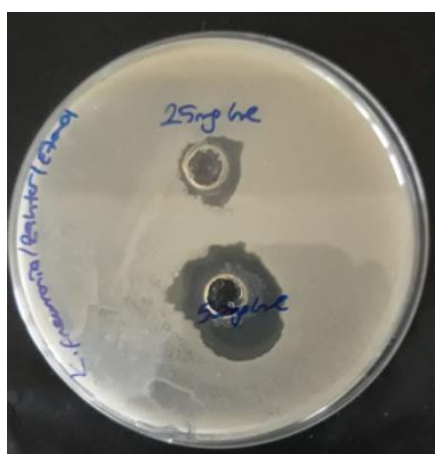

A

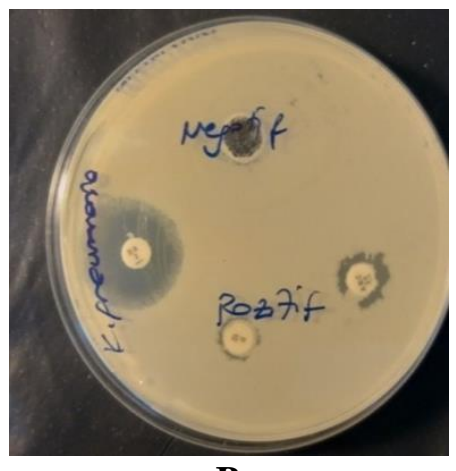

B

Şekil 2. A. $K$. pneumoniae'nın zahter ektresinin etanol çözeltisindeki inhibisyon zonları. B. $K$. pneumoniae'nın pozitif ve negatif kontrollere karşı oluşan inhibisyon zonları

Minimal İnhibisyon Konsantrasyon bulgularına göre; zahter ekstraktının etanollü çözeltisinde $K$. pneumoniae'ya karş1 \%25'lik konsantrasyonda
1:32 oranında etki ederken, \%50'lik konsantrasyonda 1:16 oranında etki ettiği belirlendi (Tablo 3).

Tablo 3. Zahter/etanol ekstresinin minimum inhibisyon konsantrasyon düzeyleri

\begin{tabular}{|c|c|c|c|c|c|c|c|c|c|c|c|c|}
\hline \multicolumn{13}{|l|}{ K. pneumoniae } \\
\hline zahter /etanol & $1 / 4$ & $1 / 8$ & $1 / 16$ & $1 / 32$ & $1 / 64$ & 1/128 & $1 / 256$ & $1 / 512$ & $1 / 1024$ & $1 / 2048$ & $1 / 4096$ & $1 / 8192$ \\
\hline$\% 25$ & & & & * & & & & & & & & \\
\hline$\% 25$ & & & & * & & & & & & & & \\
\hline$\% 50$ & & & * & & & & & & & & & \\
\hline$\% 50$ & & & * & & & & & & & & & \\
\hline$\% 75$ & & & & & & & & & & & & \\
\hline$\% 75$ & & & & & & & & & & & & \\
\hline$\% 100$ & & & & & & & & & & & & \\
\hline$\% 100$ & & & & & & & & & & & & \\
\hline
\end{tabular}

Bitki özütleri ve farklı baharat karışımları, önemli antimikrobiyal özellikler gösterebilecek biyolojik olarak aktif bileşiklerin önemli kaynaklarını oluşturur. $\mathrm{Bu}$ çalışmada, zahter ekstraktı, $K$. pneumoniae, E. coli ve $P$. aeruginosa üç farklı bakteriye karşı denenmiş olup etanol ile hazırlanan ekstre özellikle $K$. pneumoniae karş1 antibakteriyel aktivite gösterdi (Tablo 3). Kloroform ile hazırlanan ekstre ise üç bakteriye de önemli antibakteriyel aktivite gösterdi. Oyuk agar yönteminden sonra zon çapları ölçülmüş daha sonra minimal inhibisyon konsantrasyon yapılmış olup, elde edilen değerler çalışma ile paralellik gösterdi.

Yapılan bir çalışmada; Zahterin metanol ve etanol ekstrelerinin $100 \mu \mathrm{l}$ hacminde oyuk agar yöntemiyle $K$. pneumoniae (19 mm-14 mm), $S$. aureus 'a $(20 \mathrm{~mm}-18 \mathrm{~mm})$ etki ettiği tespit edilmiştir (Türkmen ve vd., 2016).

Yapılan başka bir çalışmada; Zahterin metanol ile 50 ve $100 \mathrm{mg} / \mathrm{ml}$ konsantrasyonlarda ekstresi hazırlanmıştır. Bacillus cereus NRRL-B 3711 ve
Staphylacoccus aureus 25923 suşları üzerine denenmiş olup Bacillus cereus'a karş1 100 $\mathrm{mg} / \mathrm{ml}$ 'sinde $11 \mathrm{~mm}$ çapında zon vermiş olup, Staphylacoccus aureus'a karş $150 \mathrm{mg} / \mathrm{ml}$ 'sinde 12 $\mathrm{mm}$ çapında zon vermiş olup yaptığımız çalışmaya paralellik göstermiştir (Güzeldag ve vd., 2010).

Başka bir çalışmaya göre; Agar disk difüzyon yöntemini kullanarak kekik, nane, adaçayı, karabiber ve sarımsağın antibakteriyel aktivitelerini $B$. Subtilis ve $S$. enteritidis'e karş1 bildirmiş̧lerdir. Kekik ekstresini $B$. Subtilis ve $S$. enteritidis üzerinde, adaçayı, nane ve karabiber ekstrelerine göre daha belirgin önleyici etkiler göstermiştir; ortalama zon çaplarını B. Subtilis için $20 \mathrm{~mm}$ ve $S$. Enteritidis için $15 \mathrm{~mm}$ olarak bildirmişlerdir (Al-Turki A.I., 2007). Yaptığımız çalışmada kullanmış olduğumuz baharat karışımı zahterin de içeriğinde kekik ve karabiber bulunmaktadır. Bundan dolayı yapılan bu çalışmada elde edilen sonuçların bizim sonuçlarımız ile tutarlılık göstermesi beklenen bir durumdur. 
Diğer bir çalışma da ise; tarçın ekstraktının (\%50 etanol) ve esansiyel yağlarının antimikrobiyal aktiviteleri, oyuk agar difüzyon metodu ile 10 farklı bakteri suşuna ve 7 farklı mantar türüne uygulanmıştır. Tarçının esansiyel yağının, test edilen mikroorganizmalara karşı tarçın ekstraktından daha etkili olduğu ve tespit edilen MIC değerlerinin \%1.25 ila \%5 arasında değişmekte olduğunu bildirmişlerdir. Tarçının esansiyel yağının, $B$. cereus üzerinde en güçlü etkiye sahip olduğunu belirtmişlerdir (Grupta ve vd., 2008). Literatür incelendiğinde bu tür baharat veya karışımların sahip olduğu esansiyel yağların diğer bileşenlere göre daha güçlü biyolojik aktiviteye sahip olduğu görülmektedir. Bu yüzden ekstraksiyon sırasında organik çözücüler kullanılmaktadır. Yaptığımız çalışmada zahter ekstresi çıkarılırken farklı organik çözücüler kullanılmıştır. $\mathrm{Bu}$ şekilde bu baharat karışımının ihtiva ettiği esansiyel yağları en yüksek verimle elde etmeye çalıştık. Bizim çalışmamızda elde ettiğimiz MIC değerleri Grupta ve vd., elde ettiği değerler ile paralellik göstermektedir.

Yapılan başka bir çalışmada ise, seçilmiş bazı baharat ve bitkilerin (Defne yaprağı, karabiber, kişniş (tohum ve yaprak), kimyon, sarımsak, zencefil, hardal, soğan ve soğan özü yağlarının) antibakteriyel ve antioksidan etkinliği sinerjistik etkileşimlerini değerlendirmek için yapılmıştır. Antibakteriyel sinerjik etkisi altı farklı bakteriye Bacillus cereus, Listeria monocytogenes, Micrococcus luteus, Staphylococcus aureus, Escherichia coli ve Salmonella typhimurium karşı değerlendirilmiştir. (Bag ve Chattopadhyay, 2015). Burada da yaptığımız çalışmada olduğu gibi antimikrobiyal etki oyuk agar yöntemine göre yapılmıştır. Kişniş ve kimyonun sinerjik etkisi belirtilen bakterilere karşı güçlü bir antibakteriyel etki göstermesi, bizim çalışmamızda olduğu gibi bazı baharat ve bitki karışımlarının sinerjik etkilerinin dikkate değer olduğunu göstermiş̧tir.

Bir diğer çalışmada; Kakule, kimyon ve dereotu yabanc1 otlarının antimikrobiyal aktivitesine, Campylobacter spp üzerine bakılmış olup, oyuk agar yöntemi kullanılmıştır. Daha sonra minimum inhibisyon konsantrasyon (MIK) düzeylerine bakılmıştır. Antimikrobiyal aktivite testlerinin sonuçlarına göre; kakule, kimyon ve dereotu yabanc1 otların Campylobacter spp'ye karş1 yüksek antimikrobiyal aktiviteye sahip olduğu bildirilmiştir. $\mathrm{Bu}$ çalışmanın antimikrobiyal sonuçları yaptığımız çalışma ile paralellik göstermiştir (Mutlu-Ingok ve KarbanciogluGuler., 2017).
Başka bir çalışmada ise; Rhus coriaria $L$. (Sumağın) sulu ekstresi beş farklı konsantrasyonlarda hazırlanmış olup, 12 bakteri suşunun (altı gram pozitif ve altı gram negatif) büyümesi üzerine antimikrobiyal etkisi incelenmiştir. Gram pozitif organizmalar arasında, Bacillus türleri (Bacillus cereus, Bacillus megaterium, Bacillus subtilis) MIC'leri en duyarlı olarak bulunmuş olup, (\%0.49) Listeria monocytogenes'in \%0.67'lik bir MİK gösteren en az hassas olduğu bulunduğu belirtilmiştir. Gram negatif organizmalardan Salmonella enteritidis'in $\% 0.67$ 'lik bir MIC ile en dirençli olduğu ve bunu takiben Escherichia coli Tip I, E.coli O157: H7, Proteus vulgaris ve $\% 0.63, \% 0.60, \% 0.55$ MIC değerlerine sahip olduğunu tespit etmişlerdir. (Nasar-Abbas ve Halkman., 2004). Bu da bize sumağın güçlü bir antibakteriyel etkiye sahip olduğunu gösterir ki bizim yaptığımız çalışmada bulunan zahterin içerisinde de sumak mevcut olup, güçlü bir ajan olarak tespit edilmiştir.

Yaptığımız çalışmada, zahter ekstresinin etanollü ve kloroformlu çözeltisinin dört farklı konsantrasyonu (25 mg/ml-50 mg/ml-75 mg/ml ve $100 \mathrm{mg} / \mathrm{ml}$ ) hazırlanmış olup, üç farklı bakteri (E. coli, $P$. aeruginosa ve K. pneumoniae) üzerine antimikrobiyal aktivitesi belirlendi. Zahterin etanollü ekstresinin $25 \mathrm{mg} / \mathrm{ml}$ konsantrasyonda $K$. pneumoniae'ya karşı $15 \mathrm{~mm}$ zon vermişken, $50 \mathrm{mg} / \mathrm{ml}$ konsantrasyonda ayn bakteriye $26 \mathrm{~mm}$ zon ile etki ettiği tespit edildi. Diğer bakterilere karşı ise aktivite göstermediği belirlendi.

\section{Sonuçlar}

Zahter ekstraktının farklı çözücüler ile farklı konsantrasyonları bakteriden bakteriye farklı sonuç vermektedir. Zahter ekstraktının antimikrobiyal aktivitesinin değişkenliği hedef mikroorganizmaların türlerine bağlıdır. Bunun en önemli sebebi ekstrenin içerisinde bulunan farklı baharatların içerisinde bulunan ve antibakteriyel özellik gösteren moleküllerin farklı çözücülerdeki çözünme miktarının farklı olmasından kaynaklanabilir. Bu şekilde antibakteriyel özellik gösterecek etken maddenin çözücü içerisindeki konsantrasyonu ne kadar yüksek olursa, gösterdiği etki de yüksek olacaktır. Bu anlamda kullanılan çözücü ve çözme protokolü elde edilecek antibakteriyel etki için önemli bir parametredir. Yapılacak olan daha kapsamlı çalışmalar ile bu bitkisel yağın antibakteriyel, antifungal ve antiviral etkileri konusunda daha fazla veri elde edilebilecektir. Çeşitli baharatların kombinasyonlarının oluşturduğu sinerjik etkileri bakteriler üzerinde, tek bir baharatın etkisinden 
daha fazla antimikrobiyal etkiye sahip olduğu bilinmektedir, farklı gıda ürünlerinde farklı mikroorganizmaları inhibe etmek için daha fazla baharatın etkileşimleri araştırılmalı ve değerlendirilmelidir (Liu ve vd., 2018).

\section{Teşekkür}

$\mathrm{Bu}$ çalışmanın yapılmasına katkı sağlayan Fırat Üniversitesi Fen Fakültesi Öğretim Üyesi Prof. Dr. Sevda Kırbağ'a teşekkür ederiz. Bu çalışma'nın yapılmasında laboratuvar ortamı için katkıda bulunan Firat Üniversitesi Tip Fakültesi Parazitoloji Bölümü Öğretim Üyesi Prof. Dr. Mustafa Kaplan'a teşekkür ederiz.

\section{Kaynaklar}

Al-Turki A.I., 2007. Antibacterial effect of thyme, peppermint, sage, black pepper and garlic hydrosols against Bacillus subtilis and Salmonella enteritidis. Journal of Food, Agriculture and Environment, 5, 92-94.

Azriani, A.R., Siti, A.S., Zulkifli, A., Wan Nudri, W.D. ve Hamid, A.M., 2008. Prevalence and pattern of use of herbal medicines during pregnancy in tumpat district, kelantan. Malaysian Journal of Medical Sciences, 15(3), 40-48.

Bag, A., ve Chattopadhyay, R.R., 2015. Evaluation of Synergistic Antibacterial and Antioxidant Efficacy of Essential Oils of Spices and Herbs in Combination. PLos One, 10(7), e0131321.

Buwa, L. ve Van Staden, J., 2006. Güney Afrika'da zührevi hastalıklara karşı kullanılan geleneksel şifalı bitkilerin antibakteriyel ve antifungal aktivitesi. J. Ethnopharmacol., 103, 139 - 142.

Faydaoğlu, E. ve Sürücüoğlu, M.S., 2013. Tıbbi ve aromatik bitkilerin antimikrobiyal, antioksidan aktiviteleri ve kullanım olanakları. Erzincan University Journal of Science and Technology, 6(2).

Gatta, L., Perna, F., Figura, N., Ricci, C., Holton, J., D'Anna, L., Miglioli, M. ve Vaira, D., 2003. Antimicrobial activity of esomeprazole versus omeprazole against Helicobacter pylori. J Antimicrob Chemother, 51(2), 439-442.

Gupta C., Garg A.P., Uniyal R.C. ve Kumari A., 2008. Comparative analysis of the antimicrobial activity of cinnamon oil and cinnamon extract on some food-borne microbes. African Journal of Microbiology Research, 247-251.

Güzeldag, G., Kadıŏlu, L. ve Açık, L., 2010. Antimicrobial Activity of Zahter Extract on Bacillus cereus and Staphylococcus aureus, Poster Sunumu, $6^{\text {th }}$ Conference on Medicinal and Aromatic Plants of Southeast European Countries, ISSN: 0973-1296 6:22, 67-68.

Guzeldag, G., Kadioglu, L., Mercimek, A. ve Matyar, F., 2013. Preliminary examination of herbal extracts on the inhibition of Helicobacter pylori. African Journal of Traditional, Complementary and Alternative Medicines., 11(1), 93-96.

Husin, A., 2001. Adverse effects of herbs and drugherbal interactions. Malaysian Journal of Pharmacy, 1(2), 39-44.

Liu, Q., Meng, X., Li, Y., Zhao, C.N., Tang, G.Y. ve Li, H.B., 2018. Antibacterial and Antifungal Activities of Spices. International Journal of Molecular Sciences, 18(6), 1283.

Martini, S., D'Addario, C., Colacevich, A., Focardi, S., Borghın1, F., Santucci, A., Figura, N. ve Rossi, C., 2009. Helicobacter pylori suşlarına ve böğürtlen yapraklarının (Rubus ulmifolius) ve izole edilmiş bileşiklerin antioksidan özelliklerine karşı antimikrobiyal aktivite. International Journal of Antimicrobial Agents 34(1), 50-9.

Mutlu-Ingok, A., ve Karbancioglu-Guler, F., 2017. Cardamom, Cumin, and Dill Weed Essential Oils: Chemical Compositions. Antimicrobial Activities, and Mechanisms of Action against Campylobacter spp. Molecules, 22(7), 1191.

Nasar-Abbas, S.M. ve Halkman, A.K., 2004. Antimicrobial effect of water extract of sumac (Rhus coriaria L.) on the growth of some food borne bacteria including pathogens. International Journal of Food Microbiology 97(1), 63-9.

Turkmen, F.U., Mercimek Takcı, H.A. ve Sekeroglu, N., 2016. Total Phenolic Content, Antioxidant and Antimicrobial Activities of Homemade and Industrial Samples of Breakfast Zahter. Herbal Mixture Akademik Gida, 14(3), 242-246.

Von Reis Altschul S. 1997. Exploring the herbarium. Sci Am. 236(5), 96-104. 